\title{
Predictive Value of the Fibrosis Scores in Patients with Chronic Hepatitis C Associated with Liver Fibrosis and Metabolic Syndrome
}

\author{
Hisamitsu Miyaaki, Tatsuki Ichikawa, Naota Taura, Satoshi Miuma, Hidetaka Shibata, \\ Hajime Isomoto, Fuminao Takeshima and Kazuhiko Nakao
}

\begin{abstract}
Objective We evaluated patients with chronic hepatitis $\mathrm{C}(\mathrm{CHC})$ and compared the clinical and pathological features of steatosis and metabolic syndrome to identify the risk factors for $\mathrm{CHC}$ with severe fibrosis.

Methods One hundred seventy-one patients with biopsy-confirmed CHC were included in the study: 90 males and 81 females, age $56.2 \pm 12.8$ years; 46 with obesity $\left(\mathrm{BMI} \geq 25 \mathrm{~kg} / \mathrm{m}^{2}\right) ; 51$ with hypertension; 36 with type 2 diabetes mellitus; and 20 with hypertriglyceridemia.

Results Steatosis was detected in 79 patients (46\%); 92 patients (54\%) showed no steatosis. Seventy-four patients (43\%) showed mild fibrosis and 97 patients (56\%) showed severe fibrosis. The variables that were significantly associated with steatosis were obesity [odds ratio 2.160 (1.010-4.727), $\mathrm{p}=0.046$ ] and type 2 diabetes [odds ratio $3.667(1.559-8.430), \mathrm{p}=0.027$ ]. The variables that were significantly associated with severe fibrosis were older age [odds ratio 2.675 (1.309-5.464), $\mathrm{p}=0.007$ ], obesity [odds ratio 2.156 (1.006-4.619), $\mathrm{p}=$ 0.048 ] and type 2 diabetes [odds ratio $8.739(2.845-26.846), \mathrm{p}=0.0002]$. Nagasaki $(\mathrm{N})$ score (the total number of specific risk factors, namely an older age, obesity, and type 2 diabetes) was higher in the severe fibrosis group than in the mild fibrosis group (mild fibrosis: severe fibrosis $=1.48 \pm 1.14$ vs.2.66 $\pm 94, \mathrm{p}<0.001$ ).

Conclusion Metabolic syndrome factors, including obesity and diabetes, play a critical role in the pathogenesis of fibrosis in CHC. The N score was therefore found to be a significant predictor of severe fibrosis in CHC.
\end{abstract}

Key words: chronic hepatitis C, steatosis, liver fibrosis, type 2 diabetes mellitus, obesity

(Intern Med 50: 1137-1141, 2011)

(DOI: 10.2169/internalmedicine.50.4447)

\section{Introduction}

Hepatitis $\mathrm{C}$ virus (HCV) infection is one of the most common causes of chronic liver disease, affecting 2 million persons in Japan. It can lead to end-stage liver disease and hepatocellular carcinoma. Chronic HCV infection is associated with metabolic abnormalities, including insulin resistance (1-3). We recently reported that insulin resistance is associated with interferon signalling, which plays an important role in the clearance of chronic hepatitis $\mathrm{C}$ (CHC) during interferon therapy $(4,5)$. Previous studies have demonstrated the association between metabolic syndrome and he- patic fibrosis in patients with hepatitis C (6-11). Steatosis is a frequent histological finding in chronic hepatitis $\mathrm{C}$ virus infection, one that affects disease progression and occurrence of hepatocellular carcinoma $(7,12-15)$. Hepatic steatosis is associated with metabolic syndrome and non-alcoholic steatohepatitis (NASH). We previously reported that risk factors for severe fibrosis in patients with NASH were metabolic syndrome, hypertension, and, in particular, diabetes mellitus (16). In this study, we evaluated patients with chronic hepatitis $\mathrm{C}(\mathrm{CHC})$ and compared the clinical and pathological features of metabolic syndrome to identify the risk factors for $\mathrm{CHC}$ with severe fibrosis. 
Table 1. Clinical Data of the Patient Population

\begin{tabular}{ll}
\hline age & $56.2 \pm 12.8$ \\
Gender & male: female=90:81 \\
HCV genotype $(1: 2)$ & $123: 48$ \\
HCV viral load $(\mathrm{Fmol} / \mathrm{L})$ & $5325 \pm 5297$ \\
$\mathrm{BMI}\left(\mathrm{kg} / \mathrm{m}^{2}\right)$ & $22.8 \pm 2.9$ \\
$\mathrm{BMI} \geq 25\left(\mathrm{~kg} / \mathrm{m}^{2}\right)$ & 49 cases $(29 \%)$ \\
Platelet $\left(\times 10^{4} / \mathrm{mm}^{3}\right)$ & $15.9 \pm 5.8$ \\
AST $(\mathrm{IU} / \mathrm{L})$ & $72 \pm 100$ \\
ALT $(\mathrm{IU} / \mathrm{L})$ & $93 \pm 110$ \\
Type 2 diabetes mellitus & 36 cases $(21 \%)$ \\
Hypertension & 51 cases $(30 \%)$ \\
Hyperlipidemia & 20 cases $(11 \%)$ \\
\hline
\end{tabular}

Table 2. Comparison between the Non-steatosis Group and Steatosis Group

\begin{tabular}{llll}
\hline & $\begin{array}{l}\text { Steatosis } \\
\mathrm{n}=79\end{array}$ & $\begin{array}{l}\text { Non-steatosis } \\
\mathrm{n}=92\end{array}$ & $\mathrm{p}$ value \\
Age $(\geq 60$ years old $)$ & $38(48 \%)$ & $45(48 \%)$ & $0.916^{*}$ \\
Gender (male) & $48(60 \%)$ & $42(45 \%)$ & $0.049^{*}$ \\
HCV genotype 1 & $55(69 \%)$ & $68(73 \%)$ & $0.533^{*}$ \\
HCV viral load $(\mathrm{Fmol} / \mathrm{L})$ & $4611 \pm 4872$ & $5968 \pm 5514$ & 0.109 \\
Platelet $\left(\times 10^{4} / \mathrm{mm}^{3}\right)$ & $15.4 \pm 5.7$ & $16.2 \pm 5.7$ & 0.324 \\
ALT (IU/L) & $106 \pm 139$ & $82 \pm 77$ & 0.173 \\
Obesity & $30(38 \%)$ & $19(20 \%)$ & $0.013^{*}$ \\
Diabetes mellitus & $24(36 \%)$ & $11(12 \%)$ & $0.001^{*}$ \\
Hypertension & $33(42 \%)$ & $18(20 \%)$ & $0.002^{*}$ \\
Hypertriglycerides & $13(17 \%)$ & $7(7 \%)$ & $0.070^{*}$ \\
\hline$\chi^{2}$ test & & &
\end{tabular}

\section{Methods}

This retrospective study included 171 consecutive patients with biopsy-confirmed $\mathrm{CHC}$ who were assessed between 1996 and 2008 in Nagasaki Universities and associated hospitals. Inclusion criteria were an increased serum aminotransferase level for at least 6 months; serum antiHCV (ELIZA; third generation); positive HCV RNA (PCR); negative serum HBs; and no other cause of liver disease, such as alcohol intake $>30 \mathrm{~d} / \mathrm{d}$ or autoimmune or metabolic disorders (genetic hemochromatosis). Obesity was defined as a body mass index (BMI) $>25$ according to the World Health Organization criteria (17). Type 2 diabetes was diagnosed according to International Diabetes Federation criteria (18) (fasting glucose $>110 \mathrm{mg} / \mathrm{dL}$, or previously diagnosed type 2 diabetes). Hypertension was also diagnosed according to International Diabetes Federation criteria (18) (systolic blood pressure $>130 \mathrm{mmHg}$ or diastolic blood pressure $>85 \mathrm{mmHg}$ ). Hypertriglyceridemia was diagnosed if there was documented use of anti-hypertriglyceride medications, or if fasting triglyceride levels were $>150 \mathrm{mg} / \mathrm{dL}$. All liver biopsy tissue specimens were examined using Hematoxylin-Eosin, Azan-Mallory, and silver reticulum staining. The specimens were assessed by one reviewer blinded to patient clinical and biochemical data. The diagnosis of each case was independently and histologically confirmed by liver pathologists according to the Japanese chronic hepatitis classification (New Inuyama classification) (19). Fatty change in $>5 \%$ of all areas was defined as steatosis. The patients were divided into two groups based on their degree of inflammation defined as mild activity and severe activity. Fibrosis staging was scored using a 5-grade scale: F0 indicated no fibrosis, F1 was defined as fibrous portal expansion, F2 was bridging fibrosis, F3 was bridging fibrosis with lobular distortion, and F4 indicated the presence of cirrhosis. The mild fibrosis group was defined as having a score of F0-2 and severe fibrosis was defined as a score of F3 or F4.

We defined the Nagasaki $(\mathrm{N})$ score as the total number of risk factors for severe fibrosis. The risk factors were age $(\geq$ 60 years old), obesity, and type 2 diabetes. In the $\mathrm{N}$ score, we doubled the presence of diabetes as a factor because the estimation value of DM was 2 times higher than that of the other factors (older age and obesity) in our logistic regression formula. Therefore, we defined $\mathrm{N}$ score as follows (20):

$\mathrm{N}$ score $=$ age $(\geq 60$ years old $)+$ Obesity $(\mathrm{BMI} \geq 25)+2 \times$ diabetes mellitus

The $\mathrm{N}$ score was compared with other non-invasive predictors of fibrosis stage, such as the AST to platelet ratio index (APRI), and the platelet APRI was defined as follows:

APRI=AST level $(/ \mathrm{ULN}) /$ platelet count $\left(10^{\circ} / \mathrm{L}\right) \times 100$.

Statistical significance was determined by SPSS analytical software (IBM, Armonk, NY). We used Student's t-test and the chi-square test to perform analyses. A multivariate analysis was performed using binary logistic regression analysis.

\section{Results}

Among the 171 patients, 90 males and 81 females were examined. The median body mass index (BMI) was $22.8 \pm$ $2.9 \mathrm{~kg} / \mathrm{m}^{2}$. Type 2 diabetes was diagnosed in $21 \%$ of patients, hypertension in $30 \%$, and hyperlipidemia in $11 \%$ (Table 1).

\section{Histological findings}

Steatosis was detected in 79 patients $(46 \%)$. We found mild activity in 149 patients and severe activity in 22 patients. We found no fibrosis in 18 patients (11\%) (F0); mild fibrosis in 56 patients (33\%) (F1); moderate fibrosis in 33 patients (19\%) (F2); bridging fibrosis in 30 patients (17\%) (F3); and cirrhosis in 34 patients (20\%) (F4).

\section{Steatosis}

The two steatosis groups are shown in Table 2. Males were significantly more common in the non-steatosis group than in the steatosis group ( $60 \%$ vs. $45 \%, \mathrm{p}=0.049)$. The patients with obesity ( $38 \%$ vs. $20 \%, \mathrm{p}=0.013$ ), type 2 diabetes 
Table 3. Multivariate Logistic Regression Analysis of the Association of Steatosis with the Risk of Fibrosis

\begin{tabular}{lll}
\hline & odds ratio & p value \\
Gender $($ male $)$ & $1.462(0.765 \sim 2.888)$ & 0.263 \\
Obesity $\left(\mathrm{BMI} \geq 25 \mathrm{~kg} / \mathrm{m}^{2}\right)$ & $\underline{2.160(1.010 \sim 4.227)}$ & $\underline{0.046}$ \\
Type 2 diabetes & $3.667(1.559 \sim 8.430)$ & 0.027 \\
Hypertension & $2.318(1.151 \sim 4.864)$ & 0.002 \\
\hline
\end{tabular}

Table 4. Comparison between Mild Fibrosis and Severe Fibrosis

\begin{tabular}{llll}
\hline & $\begin{array}{l}\text { Severe fibrosis } \\
\mathrm{n}=97\end{array}$ & $\begin{array}{l}\text { Mild fibrosis } \\
\mathrm{n}=74\end{array}$ & $\mathrm{p}$ value* \\
Age $(\geq 60$ years old) & $56(59 \%)$ & $23(32 \%)$ & $0.001^{*}$ \\
gender (male) & $51(52 \%)$ & $39(52 \%)$ & $0.987^{*}$ \\
$\mathrm{HCV}$ genotype 1 & $73(75 \%)$ & $50(67 \%)$ & $0.348^{*}$ \\
$\mathrm{HCV}$ viral load & $5924 \pm 5490$ & $4864 \pm 5035$ & 0.214 \\
Platelet $\left(\times 10^{4} / \mathrm{mm}^{3}\right)$ & $13.5 \pm 4.7$ & $19.0 \pm 5.4$ & $<0.001$ \\
ALT & $104.2 \pm 129.9$ & $79.5 \pm 77.7$ & 0.126 \\
obesity & $34(31 \%)$ & $15(20 \%)$ & $0.034^{*}$ \\
Type 2 diabetes & $32(33 \%)$ & $4(5 \%)$ & $<0.001^{*}$ \\
Hypertension & $35(38 \%)$ & $16(18 \%)$ & $0.041 *$ \\
Hypertriglyceride & $11(11 \%)$ & $9(12 \%)$ & $0.868 *$ \\
\hline$\chi^{2}$ test & & &
\end{tabular}

( $36 \%$ vs. $12 \%, \mathrm{p}=0.001)$, and hypertension $(42 \%$ vs. $20 \%$, $\mathrm{p}=0.002$ ) were significantly more likely to be in the nonsteatosis group than the steatosis group. There were no significant differences between the other clinical features (age, incidence of the HCV genotype, HCV viral load, ALT, platelet count, hypertriglycemia). In a multivariate logistic regression analysis, obesity, type 2 diabetes, and hypertension were independent predictors for steatosis [odds ratio 2.160 (1.010-4.227), $\mathrm{p}=0.046$, odds ratio 3.667 (1.5598.430), $\mathrm{p}=0.027$, odds ratio $2.318(1.151-4.864), \mathrm{p}=0.002)]$ (Table 3).

The incidence of severe activity was not significantly different between the two groups (non-steatosis group: steatosis group $=9.7 \%: 16.4 \%, \mathrm{p}=0.2849)$.

\section{Severe fibrosis risk factors}

The risk factors of the two fibrosis groups are shown in Table 4 . The prevalence of older patients ( $\geq 60$ years old) in the severe fibrosis group was significantly greater than that of younger patients (32\% vs. 59\%, p=0.001). The prevalence of obesity, type 2 diabetes, and hypertension was significantly higher in the severe fibrosis group than in the mild fibrosis group $(31 \%$ vs. $20 \%, \mathrm{p}=0.034,33 \%$ vs. $5 \%$, p $<0.001,38 \%$ vs. $18 \%, \mathrm{p}=0.041$, respectively). The platelet count was significantly lower in the severe fibrosis group than in the mild fibrosis group $(13.5 \pm 4.7$ vs. $19.0 \pm 5.4$, < 0.001). There were no significant differences between the other clinical features (age, incidence of the HCV genotype,
Table 5. A Multivariate Logistic Regression Analysis of the Association of Severe Fibrosis with Various Risk Factors

\begin{tabular}{lll}
\hline & Odds ratio & \\
Age $(60$ years old $)$ & $\underline{2.675(1.309 \sim 5.464)}$ & $\underline{0.007}$ \\
Obesity & $2.156(1.006 \sim 4.619)$ & 0.048 \\
Type 2 DM & $8.739(2.845 \sim 26.846)$ & 0.0002 \\
Hypertension & $1.087(0.487 \sim 2.426)$ & 0.8394 \\
\hline
\end{tabular}

HCV viral load, ALT, hypertriglycemia). In a multivariate logistic regression analysis, older age, type 2 diabetes, and obesity were independent predictors for severe fibrosis [coefficient 0.984 odds ratio 2.675 (1.309-5.464), $\mathrm{p}=0.007$, coefficient 2.168 odds ratio 8.739 (2.845-26.846), $\mathrm{p}=0.0002$, coefficient 0.768 odds ratio $2.156(1.006-4.619), \mathrm{p}=0.048)$ ] (Table 5).

The fibrosis stage was significantly worse in the steatosis group than in the non-steatosis group $(1.78 \pm 1.28$ vs. $2.34 \pm$ 1.29, $\mathrm{p}=0.005$ ).

\section{Predictive score of severe fibrosis}

The $\mathrm{N}$ score is the total number of risk factors, including: older age ( $\geq 60$ years old), obesity, and type 2 diabetes. $\mathrm{N}$ score were significantly higher in the severe fibrosis group than in the mild fibrosis group $(1.48 \pm 1.14$ vs. $2.66 \pm 94, \mathrm{p}<$ 0.001).

We found that 17 of 53 patients (32\%) with an $\mathrm{N}$ score of 0 had severe fibrosis, 31 of $63(49 \%)$ with an $\mathrm{N}$ score of 1 , 25 of $29(86 \%)$ with an $\mathrm{N}$ score of 2,21 of $23(91 \%)$ patients with an $\mathrm{N}$ score of 3 , and 3 of $3(100 \%)$ patients with an $\mathrm{N}$ score of 4 had severe fibrosis.

The ROC curve (Fig. 1) shows the respective sensitivities and specificities for any combination of 1 to 4 of the $\mathrm{N}$ score. An $\mathrm{N}$ score of 2 provides the best combination of sensitivity (0.50) and specificity (0.91) for predicting severe fibrosis.

Compared with other non-invasive predictors of significant fibrosis, the sensitivity and specificity of an APRI of 1.5 were $46 \%$ and $93 \%$, and those for a platelet count of $12 \times 10^{4} / \mathrm{mm}^{3}$ were $44 \%$ and $91 \%$.

\section{Discussion}

In this study, we analyzed the correlation between metabolic syndrome and pathological findings in CHC patients, and identified the clinical risk factors for severe fibrosis.

Obesity, type 2 diabetes, and hypertension were significant risk factors for severe steatsosis and fibrosis. These comorbidities of metabolic syndrome affected steatosis and the progression of severe fibrosis in the liver. Previous data suggest a strong association between the presence of steatosis and severe fibrosis in $\mathrm{CHC}(7,12,13)$. In this study, patients in the steatosis group had more severe fibrosis than 


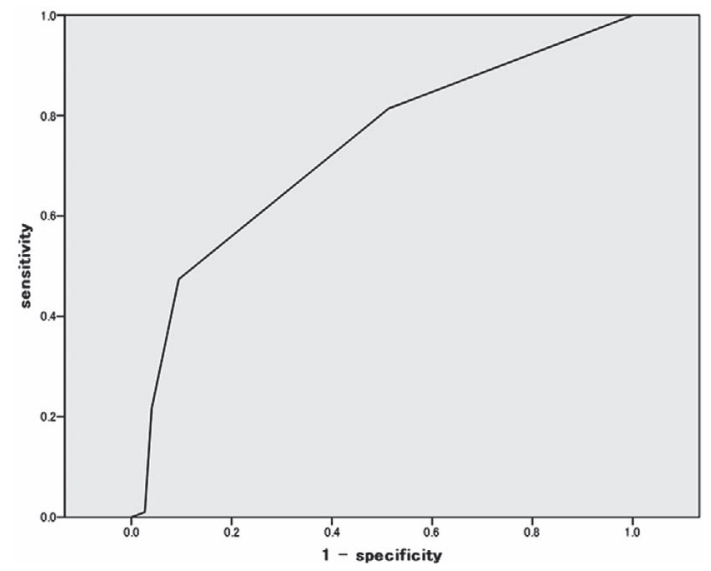

Figure 1. ROC curve for the Nagasaki (N) score. A cut-off $N$ score of 2 gives the sensitivity $(0.50)$ and specificity $(0.91)$. The area under the ROC curve is $\mathbf{0 . 7 3 2}$.

Table 6. The Incidence of Severe Fibrosis in Patients with Different $\mathrm{N}$ Scores

\begin{tabular}{ll}
\hline & Severe fibrosis \\
N Score 0 & $17 / 53(32 \%)$ \\
N Score 1 & $31 / 63(49 \%)$ \\
N Score 2 & $25 / 29(86 \%)$ \\
N Score 3 & $21 / 23(91 \%)$ \\
N Score 4 & $3 / 3(100 \%)$ \\
\hline
\end{tabular}

those in the non-steatosis group. It remains controversial whether or not hepatic steatosis may accelerate fibrosis by stimulating the activity of CHC. In this study, the ALT levels and the incidence of severe inflammation in the steatosis group were not significantly higher than in the non-steatosis group. Therefore, hepatic steatosis may not promote liver fibrosis by liver cell injury.

Evidence indicates that hepatic steatosis, which is affected by metabolic syndrome, may accelerate the progression of fibrosis in patients with $\mathrm{CHC}$. The findings are consistent with those from other reports that demonstrate an association between effective weight loss and reductions in steatosis, ALT levels, and fibrosis stage in patients with CHC (21).

$\mathrm{HCV}$ core protein increases reactive oxygen species (ROS) and lipid peroxidation, leading to liver damage and fibrosis $(22,23)$. Core protein also reduces microsomal triglyceride transport protein function, leading to hepatic steatosis. Infection with the HCV virus affects liver steatosis as well as fibrosis (24). Thus, both host and viral factors induce steatosis and play a role in severe fibrosis in chronic hepatitis $\mathrm{C}$.

We found a significant correlation between the severity of hepatic fibrosis and the comorbidites of metabolic syndrome, including obesity, diabetes mellitus, and hyperten- sion. Our previous study showed that metabolic syndrome, including diabetes mellitus and hypertension, was a risk factor for severe fibrosis in patients with NASH (16). These risk factors in patients with NASH were similar to those in $\mathrm{CHC}$ patients, suggesting that the mechanism underlying the liver fibrosis in $\mathrm{CHC}$ patients resembles that of NASH.

Type 2 diabetes and obesity are correlated with insulin resistance. We previously reported that the development of liver fibrosis is associated with insulin resistance in CHC patients (25). Outcomes from the present study show the adverse effects of insulin resistance on liver fibrosis in $\mathrm{CHC}$ patients.

Previous data also have shown that obesity and diabetes mellitus are associated with progression of fibrosis in CHC $(6,8,9,26)$. Few prior studies have been conducted in Asian patients. The present study shows that metabolic syndrome, including obesity and diabetes, also predict severe fibrosis in Asian patients.

Taken together, although steatosis, fibrosis and metabolic syndrome seem to be associated with each other, our crosssectional study did not identify any associations between these factors. Further studies will be necessary to confirm whether these conditions are associated, or whether they act as independent risk factors.

We defined the $\mathrm{N}$ score as the total number of risk factors for severe fibrosis. The risk factors were age ( $\geq 60$ years old), obesity, and type 2 diabetes. In the $\mathrm{N}$ score, we doubled the presence of diabetes as a factor because the estimation value of DM was 2 times that of other factors (older age and obesity) in our logistic regression formula (risk factor). The $\mathrm{N}$ score was significantly higher in the severe fibrosis group than in the mild fibrosis group. About $90 \%$ of the patients in the severe fibrosis group had an $\mathrm{N}$ score $\geq 2$. An $\mathrm{N}$ score $\geq 2$ indicates a high risk for severe fibrosis. Our results suggest that half of the patients in the severe fibrosis group also had metabolic disorders, including diabetes and obesity. Conversely, there was no association between metabolic syndrome and other factors.

While the specificity of the $\mathrm{N}$ score $(0.91)$ is very good, the sensitivity $(0.5)$ is not sufficient. This suggests that there are two or more mechanisms underlying the progression of fibrosis, and metabolic syndrome represents one of them.

Compared to other non-invasive markers, the sensitivity and specificity of the $\mathrm{N}$ score was equal to the platelet count and APRI. The $\mathrm{N}$ score is a simple score to calculate, and it adds together the three risk factors. Therefore, determining the $\mathrm{N}$ score is considered to be an easy way to predict the presence of severe liver fibrosis in CHC patients.

The present study has limitations. We cannot perform a validation due to the fact that our sample size was so small. Now, we are planning to perform a validation set to confirm the value of $\mathrm{N}$ score.

In conclusion, older age, obesity and type 2 diabetes are significant predictors of severe fibrosis in Japanese CHC patients. The total number of these risk factors in patients could be a useful marker for predicting severe fibrosis in pa- 
tients with $\mathrm{CHC}$.

The authors state that they have no Conflict of Interest (COI).

\section{References}

1. Koike K. Hepatitis $\mathrm{C}$ as a metabolic disease: Implication for the pathogenesis of NASH. Hepatol Res 33: 145-150, 2005.

2. Moucari R, Asselah T, Cazals-Hatem D, et al. Insulin resistance in chronic hepatitis C: association with genotypes 1 and 4 , serum HCV RNA level, and liver fibrosis. Gastroenterology 134: 416423, 2008.

3. Sheikh MY, Choi J, Qadri I, Friedman JE, Sanyal AJ. Hepatitis C virus infection: molecular pathways to metabolic syndrome. Hepatology 47: 2127-2133, 2008.

4. Miyaaki H, Ichikawa T, Nakao K, et al. Predictive value of the phosphorylation of signal transducers and activators of transcription in the outcome of interferon therapy for chronic hepatitis C. Intervirology 51: 394-399, 2008.

5. Miyaaki H, Ichikawa T, Nakao K, et al. Predictive value of suppressor of cytokine signal 3 (SOCS3) in the outcome of interferon therapy in chronic hepatitis C. Hepatol Res 39: 850-855, 2009.

6. Hu KQ, Kyulo NL, Esrailian E, et al. Overweight and obesity, hepatic steatosis, and progression of chronic hepatitis C: a retrospective study on a large cohort of patients in the United States. J Hepatol 40: 147-154, 2004.

7. Adinolfi LE, Gambardella M, Andreana A, Tripodi MF, Utili R, Ruggiero G. Steatosis accelerates the progression of liver damage of chronic hepatitis $\mathrm{C}$ patients and correlates with specific $\mathrm{HCV}$ genotype and visceral obesity. Hepatology 33: 1358-1364, 2001.

8. Hwang SJ, Luo JC, Chu CW, et al. Hepatic steatosis in chronic hepatitis $\mathrm{C}$ virus infection: prevalence and clinical correlation. J Gastroenterol Hepatol 16: 190-195, 2001.

9. Clouston AD, Powell EE, Walsh MJ, Richardson MM, Demetris AJ, Jonsson JR. Fibrosis correlates with a ductular reaction in hepatitis C: roles of impaired replication, progenitor cells and steatosis. Hepatology 41: 809-818, 2005.

10. Tsochatzis EA, Manolakopoulos S, Papatheodoridis GV, Archimandritis AJ. Insulin resistance and metabolic syndrome in chronic liver diseases: old entities with new implications. Scand J Gastroenterol 44: 6-14, 2009.

11. Svegliati-Baroni G, Bugianesi E, Bouserhal T, et al. Post-load insulin resistance is an independent predictor of hepatic fibrosis in virus $\mathrm{C}$ chronic hepatitis and in non-alcoholic fatty liver disease. Gut 56: 1296-1301, 2007.

12. Giannini E, Ceppa P, Botta F, et al. Steatosis and bile duct damage in chronic hepatitis $\mathrm{C}$ : distribution and relationships in a group of Northern Italian patients. Liver 19: 432-437, 1999.

13. Hourigan LF, Macdonald GA, Purdie D, et al. Fibrosis in chronic hepatitis $\mathrm{C}$ correlates significantly with body mass index and steatosis. Hepatology 29: 1215-1219, 1999.

14. Ohata K, Hamasaki K, Toriyama K, et al. Hepatic steatosis is a risk factor for hepatocellular carcinoma in patients with chronic hepatitis C virus infection. Cancer 97: 3036-3043, 2003.

15. Tanaka A, Uegaki S, Kurihara H, et al. Hepatic steatosis as a possible risk factor for the development of hepatocellular carcinoma after eradication of hepatitis $\mathrm{C}$ virus with antiviral therapy in patients with chronic hepatitis C. World J Gastroenterol 13: 51805187, 2007.

16. Miyaaki H, Ichikawa T, Nakao K, et al. Clinicopathological study of nonalcoholic fatty liver disease in Japan: the risk factors for fibrosis. Liver Int 28: 519-524, 2008.

17. World Health Organization. Difinition and Classification of Diabetes Mellitus and its Complications-Part 1: Diagnosis and Classification of Diabetes Mellitus. World Health Organization, 1999: 20-21.

18. Alberti KG, Zimmet P, Shaw J; IDF Epidemiology Task Force Consensus Group. The metabolic syndrome--a new worldwide definition. Lancet 366: 1059-1062, 2005.

19. Ichida F, Tsuji T, Omata $M$, et al. New Inuyama classification; New criteria for histological assesment of chronic hpatitis. Int Hepatol Commun 6: 112-119, 1996.

20. Wai CT, Greenson JK, Fontana RJ, et al. A simple noninvasive index can predict both significant fibrosis and cirrhosis in patients with chronic hepatitis C. Hepatology 38: 518-526, 2003.

21. Hickman IJ, Clouston AD, Macdonald GA, et al. Effect of weight reduction on liver histology and biochemistry in patients with chronic hepatitis C. Gut 51: 89-94, 2002.

22. Korenaga M, Wang T, Li Y, et al. Hepatitis C virus core protein inhibits mitochondrial electron transport and increases reactive oxygen species (ROS) production. J Biol Chem 280: 3748137488, 2005.

23. Dionisio N, Garcia-Mediavilla MV, Sanchez-Campos S, et al. Hepatitis C virus NS5A and core proteins induce oxidative stressmediated calcium signalling alterations in hepatocytes. J Hepatol 50: 872-882, 2009.

24. Perlemuter G, Sabile A, Letteron $P$, et al. Hepatitis $C$ virus core protein inhibits microsomal triglyceride transfer protein activity and very low density lipoprotein secretion: a model of viralrelated steatosis. Faseb J 16: 185-194, 2002.

25. Taura N, Ichikawa T, Hamasaki K, et al. Association between liver fibrosis and insulin sensitivity in chronic hepatitis C patients. Am J Gastroenterol 101: 2752-2759, 2006.

26. Mason AL, Lau JY, Hoang N, et al. Association of diabetes mellitus and chronic hepatitis C virus infection. Hepatology 29: 328333, 1999.

(C) 2011 The Japanese Society of Internal Medicine http://www.naika.or.jp/imindex.html 